\title{
Investigation of a Temperature Field of the Steel Billet 150x150 mm Continuously Cast
}

\author{
František Kavička ${ }^{1,{ }^{*}}$, Jaroslav Katolický ${ }^{1}$, Josef Štětina $^{1}$, Tomáš Mauder ${ }^{1}$, and Lubomír \\ Klimeš $^{1}$
}

${ }^{1}$ Brno University of Technology, Faculty of Mechanical Engineering, Czech Republic

\begin{abstract}
The solidification and cooling of a continuously cast billet and the simultaneous heating of the mold is a very complicated problem of three-dimensional (3D) transient heat and mass transfer. The solving of uch a problem is impossible without numerical models of the temperature field of the concasting itself which it is being processed through the concasting machine (caster). The application of the numerical model requires systematic experimentation and measurement of operational parameters on a real caster as well as in the laboratory. The measurement results, especially temperatures, serve not only for the verification of the exactness of the model, but mainly for optimization of the process procedure. The most important part of the investigation is the measurement of the temperatures in the walls of the mold and the surface of the slab in the zones of secondary and tertiary cooling.
\end{abstract}

\section{Introduction}

The optimization of production on casters, with the aim of achieving maximum savings and maximum quality of the product is unthinkable without knowledge of the course of solidification and cooling of the concasting [1-3]. Solidification and cooling of a concasting, with the simultaneous heating of the mould, is a very complex problem of transient heat and mass transfer. The temperature field in the concasting is determined by using the transient 3D enthalpy balance equation with the Finite Differences Method. It depends on the alloy composition and its thermophysical properties as well as on the cooling rate and shift rate [4-8].

The temperature distribution in the concasting is described by the enthalpy balance equation

$\rho \frac{\partial H_{v}}{\partial \tau}+\frac{\partial}{\partial x}\left(\rho \cdot u \cdot H_{v}\right)+\frac{\partial}{\partial y}\left(\rho \cdot v \cdot H_{v}\right)+\frac{\partial}{\partial z}\left(\rho \cdot w \cdot H_{v}\right)=\frac{\partial}{\partial x}\left(k \frac{\partial T}{\partial x}\right)+\frac{\partial}{\partial y}\left(k \frac{\partial T}{\partial y}\right)+\frac{\partial}{\partial z}\left(k \frac{\partial T}{\partial z}\right)$

The solution is performed with the boundary conditions:

$T=T_{\text {cast }}$

at the meniscus

$$
-k \frac{\partial T}{\partial n}=0
$$

\footnotetext{
* Corresponding author: kavicka@fme.vutbr.cz
} 
at the plane of symmetry

$-k \frac{\partial T}{\partial n}=h\left(T_{\text {surf }}-T_{\text {mould }}\right)$

in the mould $-k \frac{\partial T}{\partial n}=h\left(T_{\text {surf }}-T_{\text {amb }}\right)+\sigma \varepsilon\left(T_{\text {surf }}^{4}-T_{\text {amb }}^{4}\right)$

The heat-transfer coefficient (HTC) h is a function of the local cooling intensity, shift rate and surface temperature, the temperature Tamb is the cooling water temperature in the secondary-cooling zone, where only radiation occurs. Based on the results of previous investigations, the boundary conditions are set identically within each zone individually. This requires a very fine grid, which leads to a large number of equations to solve.

\section{Determining the main boundary conditions}

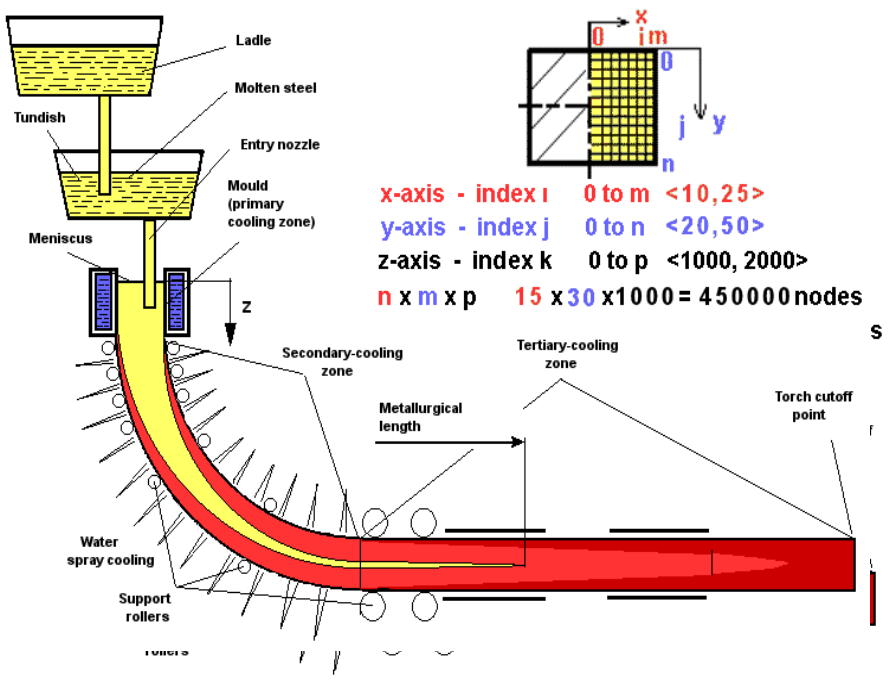

Fig. 1. Diagram of typical radial billet caster.
Figure 1 shows a diagram of a typical radial billet caster. There are three areas with different boundary conditions [9-12]:

- The primarycooling zone - the mould.

- The secondarycooling zone - where the billet is cooled by spraying.

- The tertiarycooling zone - the area where the billet is cooled by the surrounding air.

The mould of a billet caster comprises a copper pipe of square cross-section whose walls are cooled by water flowing inside. The heat flow released from the solidifying steel in the mould must be equal to the heat released through the flowing water

$$
\dot{Q}=c_{w} \cdot \rho_{w} \cdot F \cdot\left(T_{\text {out }}-T_{\text {in }}\right)
$$

The heat flow must be transferred from the solidifying steel to the wall of the mould and then into the cooling water. Therefore, the $H T C$ for the equation for the boundary condition in the secondary-cooling zone, is determined from.

$$
h=\frac{\dot{Q}}{S \cdot\left(T_{\text {solid }}-T_{\text {out }}\right)}
$$

where $S$ is the area of the inside surface of the mould.

The second most important part of the mould which affects the correct solidification of the billet during pouring are the cooling water-jets positioned inside the secondary-cooling zone. In order for the model to function correctly, it is necessary to determine the correct value of the HTC underneath the jet. There exist a number of empirical equations for calculating the HTC, however, these have proven to be inaccurate for the $3 \mathrm{D}$ model. 
Therefore, extensive experimentation had been conducted on a laboratory device simulating the process of solidification within the secondary-cooling zone (Figure 2).

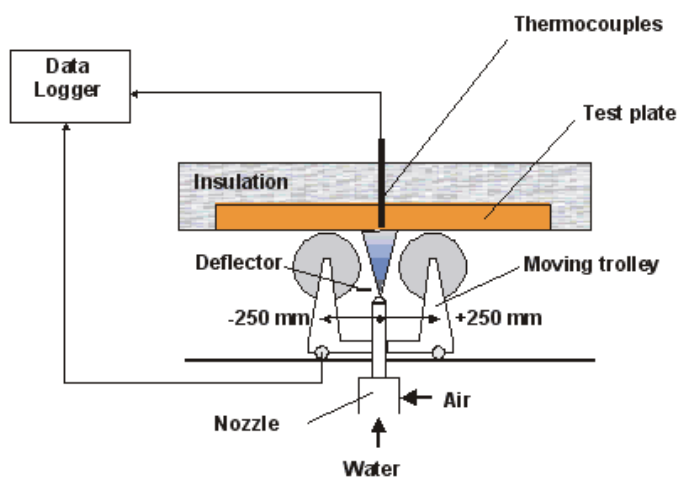

Fig. 2. Laboratory device simulating the process of cooling.

The values of the HTCs underneath the water jets were obtained via an inverse task which used the temperatures measured in the cooled surface. (The calculated HTCs are a function of the surface temperature.) These measurements were conducted for various operation conditions, i.e. the pressure of the water and the shift rate. The numerical model contains a function which, based on the entered water pressure, shift rate, positions of the jet and the surface temperature, calculates the current $H T C[10,11]$.

It is assumed that in the tertiary-cooling zone there is natural convection $\left(h_{c}\right)$ in the area that is neither cooled by the water jets nor by rollers. The equation (6) was published by A. Richard [13]:

$$
h_{c}=0.84 \sqrt[3]{\left(T-T_{a m b}\right)}
$$

Radiation $\left(h_{r}\right)$ occurs on the entire surface of the billet (except for the areas underneath the rollers) - even under the jets. It is therefore necessary to add the HTC corresponding to the radiation.

$$
h_{r}=\varepsilon \cdot \sigma \cdot\left(T^{2}+T_{a m b}^{2}\right) \cdot\left(T+T_{a m b}\right)
$$

All HTCs that had been calculated - in the relevant areas - using the above-mentioned methods. For the range of temperatures on the surface of the billet, $\varepsilon \approx 0.8$. Experimentation has proved that the emissivity of the surface of the billet is not constant but can be determined empirically. The resultant HTC was obtained by adding the individual coefficients. In the area of the natural convection it was obtained as the sum of the coefficients of heat-transfer by convection and radiation. In the area beneath the jet, the resultant $H T C$ was obtained as the sum of the coefficients of the heat-transfer calculated by an inverse task in the laboratory and radiation. In the area under the roller, the resultant $H T C$ is equal to the HTC whose calculation is described above. In the areas where the ranges of measurement between individual jets overlap, in each case, the HTC with the higher value was considered as the correct one.

\section{Experiments in the operation}

It is necessary to tune the model and verify it according to measurement results from a real caster [14]. In this case, the temperature of the wall of a pipe mould-crystallizer (using 
thermocouples - Figure 3) and the surface temperatures were measured (using pyrometers Figure 4) in the secondary- and tertiary-cooling zones. Figure 5 shows the positions of pyrometers there. Figure 6 brings an example of the measured and calculated under a pyrometer.
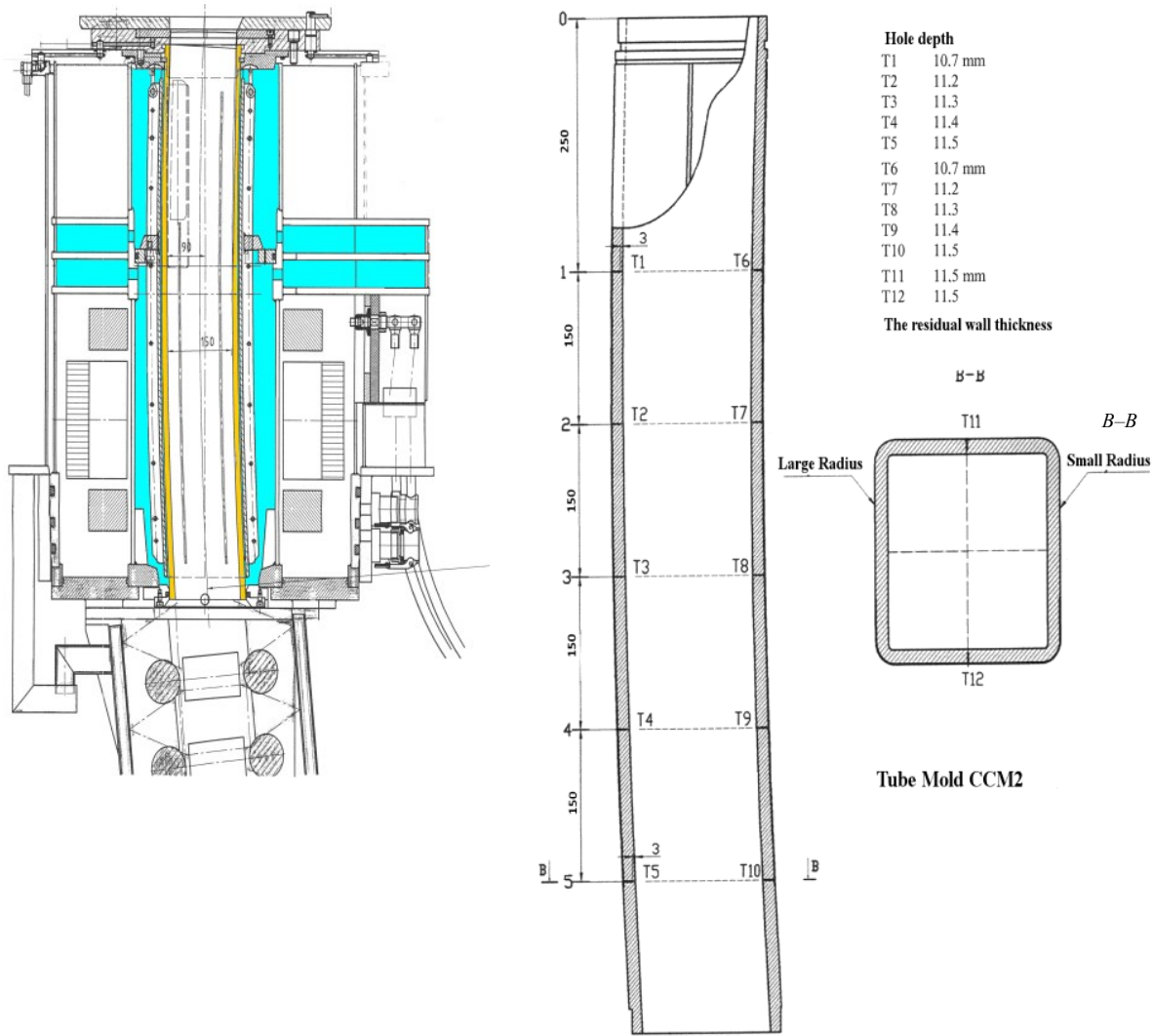

Fig. 3. Schema of the pipe crystallizer and thermocouples position.
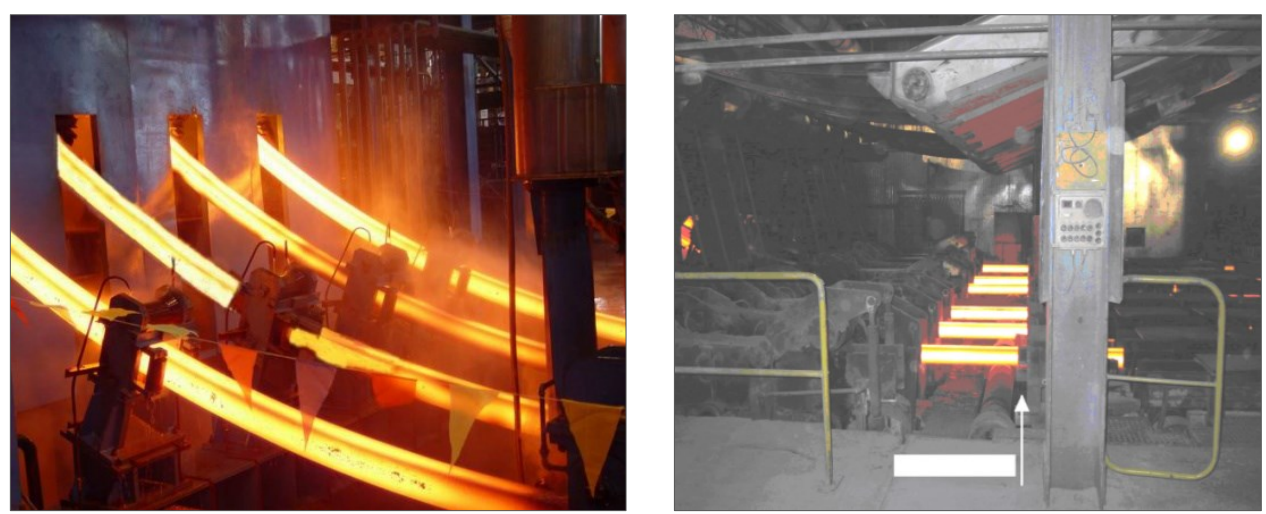

Fig. 4. The place of temperature measurement. 


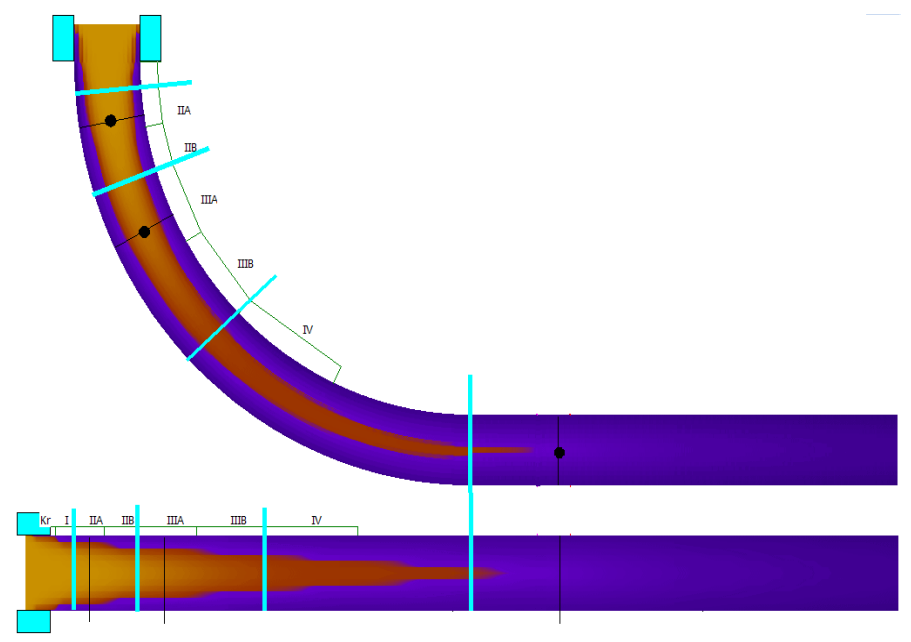

Fig. 5. The positions of the pyrometers in the secondary- and tertiary-cooling zones.

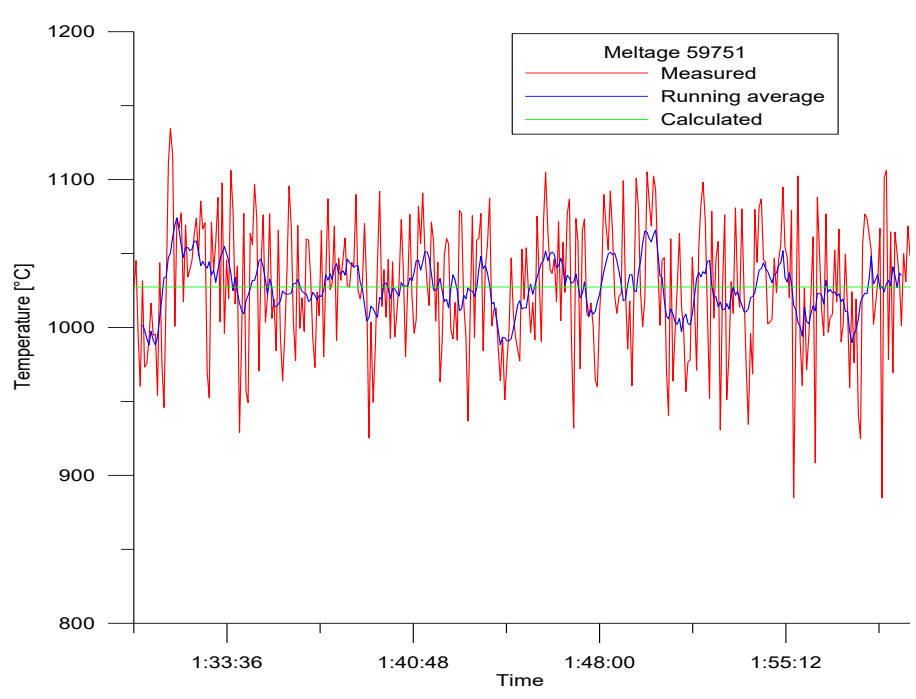

Fig. 6. Temperature history graph.

\section{Application of the numerical model}

The numerical model is applied in order to investigate a concast steel (30MnVS6) billet in any stage of the process. In order to determine the density of the mesh, the billet was analyzed in only one of its symmetrical halves (Figure 1). The selected density was 15 unit volumes in the x-direction, 30 unit volumes in the y-direction and 1000 in the z-direction, which is the direction of a movement of the billet. The time step was selected within the range from 0.1 to 0.5 seconds and depends on the shift rate. A time step greater than $0.5 \mathrm{~s}$ does not guarantee a numerically stable results. The temperature field of the billet was simulated for the shift rate 2 and $3 \mathrm{~m} / \mathrm{min}$.

After the computation it is possible to obtain the temperatures at each node of the mesh and at any time of the process [7,9]. Very useful are the 2D curves. Each curve shows the 
temperature history at user defined point of the cross-section of the billet. Figure 7 represents these temperature-distance from the level curves graphically for the shift rate $2 \mathrm{~m} / \mathrm{min}$ and Figure 8 for the shift rate $3 \mathrm{~m} / \mathrm{min}$.

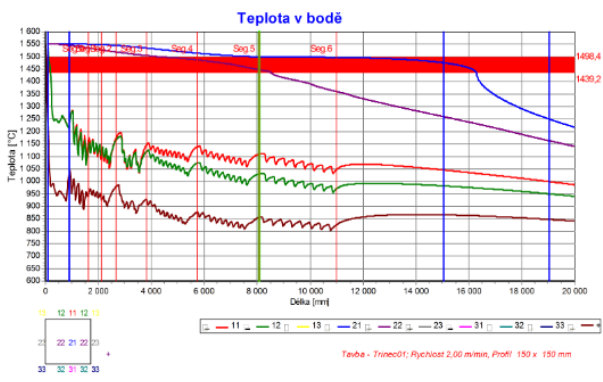

Fig. 7. The temperature history in selected points of the cross-section of the billet (shift rate $2 \mathrm{~m} / \mathrm{min}$ ).

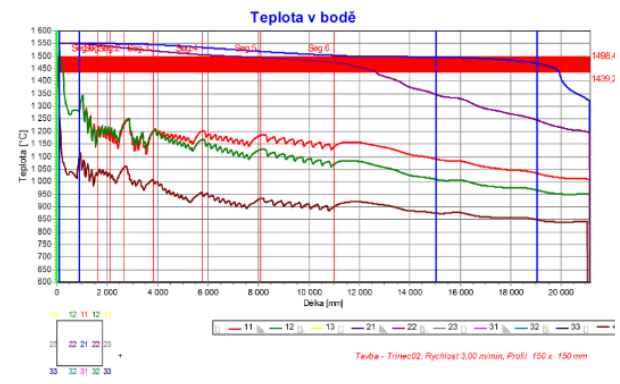

Fig. 8. The temperature history selected points of the cross-section of the billet (shift rate $3 \mathrm{~m} / \mathrm{min}$ ).

The software allows the user to display or print the temperature field used isotherms or isozones or both whenever necessary. Figure 9 and 10 show the temperature field in the longitudinal sections of the billet for the shift rate $2 \mathrm{~m} / \mathrm{min}$ and $3 \mathrm{~m} / \mathrm{min}$. by means of isozones. Both figures represent also temperature isozones of the cross sections of the billet at different distances under the level in a mould. It is possible also to see a cone of solidification and its apex, i.e. a metallurgical lengths.

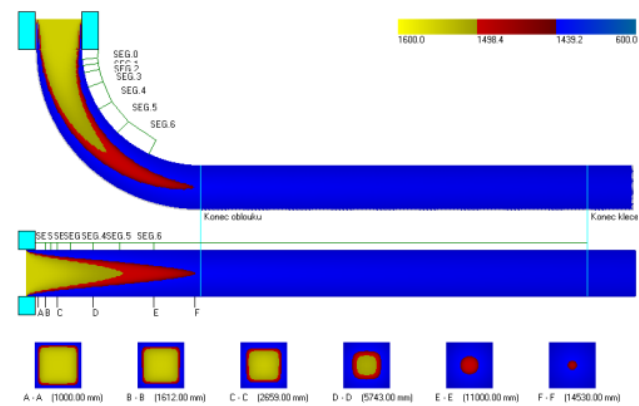

Fig. 9. The temperature field of the longitudinal sections and cross sections of the billet (shift rate $2 \mathrm{~m} / \mathrm{min}$ ).

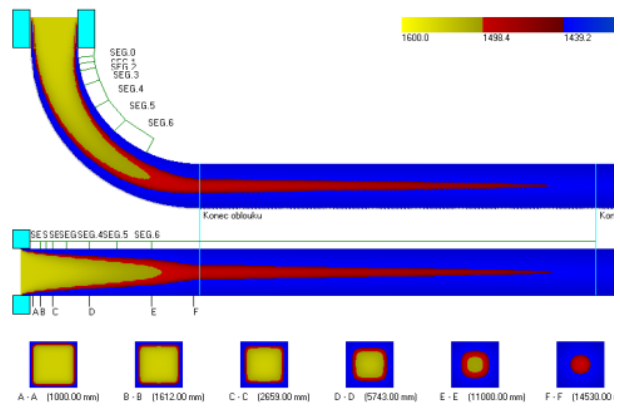

Fig. 10. The temperature field of the longitudinal sections and cross sections of the billet (shift rate $3 \mathrm{~m} / \mathrm{min}$ ).

\section{Conclusion}

Research into the thermokinetics of solidification and cooling of concast billets requires systematic experimental measurement on a real caster. Its results are utilised not only for improving the numerical model, of the temperature field, but also for assessing the exactness of this model. This dynamic model, which works non-stop in real time, ensures continuous correction of the real process of the caster in question. The main measured quantities are the temperature in the walls of the mould, the surface temperatures of the slab upon exit from the mould, at the unbending point of the slab and upon exit from the cage of the secondary cooling. Furthermore, it is the casting temperature, the casting speed, the temperature of the cooling water, the metallurgical length, etc. A specialised laboratory conducts measurements of the spraying characteristics of individual cooling nozzles. 
Its output establishes the heat transfer coefficients beneath each of the water or water-air nozzles.

This research was supported through the Czech Science Foundation under project No. 19-20802S.

\section{Nomenclature}

$\begin{array}{lll}c & \text { specific heat capacity } & {\left[\mathrm{J} \cdot \mathrm{kg}^{-1} \cdot \mathrm{K}^{-1}\right]} \\ h & \text { heat transfer coefficient (HTC) } & {\left[\mathrm{W} \cdot \mathrm{m}^{-2} \cdot \mathrm{K}^{-1}\right]} \\ H_{v} & \text { specific volume enthalphy } & {\left[\mathrm{J} \cdot \mathrm{m}^{-3}\right]} \\ k & \text { heat conductivity } & {\left[\mathrm{W} \cdot \mathrm{m}^{-1} \cdot \mathrm{K}^{-1}\right]} \\ n & \text { normal to the surface } & {[\mathrm{m}]} \\ T & \text { temperature } & {[\mathrm{K}]} \\ T_{\text {solid, }} & \text { solid temperature } & {[\mathrm{K}]} \\ T_{w, \text { out }}, T_{w, \text { in }} & \text { water temperature (in, out the mould) } & {[\mathrm{K}]} \\ T_{\text {surf }, T_{\text {amb }}} & \text { surface, ambient (cooling water temperature) } & \\ T_{\text {cast }}, T_{\text {mould }} & \text { casting, mould temperature } & {[\mathrm{K}]} \\ x, y, z & \text { axes in given directions } & {[\mathrm{K}]} \\ u, v, w & \text { shift rate in given direction } & {[\mathrm{m}]} \\ \rho & \text { density } & {\left[\mathrm{m} \cdot \mathrm{s}^{-1}\right]} \\ \tau & \text { time } & {\left[\mathrm{kg} \cdot \mathrm{m}^{-3}\right]} \\ \sigma & \text { Stefan-Boltzmann constant }\left(=5.76 \times 10^{-6}\right) & {[\mathrm{s}]} \\ \varepsilon & \text { emmisivity }(=0.8) & {\left[\mathrm{Wm}{ }^{-2} \mathrm{~K}^{-4}\right]} \\ & & {[-]}\end{array}$

\section{References}

1. B. G. Thomas, R. J. O’Malley, D. T. Stone, Model. Of Cast. Weld., Solidif. Proc. VIII, San Diego, CA, TMS (1998)

2. J. K. Brimacombe, Metall. and Mater. Trans. B, 30B, 553 (1999)

3. S. Chaudhuri, et al., ISA Trans. 49,1 (2010)

4. J. Stetina, et al., Proc. of 5th Pac. Inter. Conf. on Adv.Mate and Process., Peking, China (2004)

5. J. Miettinen, S. Louhenkilpi, J. Laine, Proc. of Gen. COST 512 Workshop (1996)

6. J. Stetina, et al., Mater. Science Forum, 475-479, Switzerland (2005)

7. F. Kavicka, et al., Proc. of $3^{\text {rd }}$ Inter. Conf. ICAMT 2004, Kuala Lumpur, Malaysia, (2004)

8. J. Miettinen, et. al., Math.\&Comp. in Sim. 80, 7 (2010)

9. J .Stetina, Assoc. professor. \& habilit. thesis, TU Ostrava, Czech Rep. (2008)

10. J. Horsky, M. Raudensky, Proc. of $14^{\text {th }}$ Inter. Metal. \& Mater. Conf. METAL, Hradec n/M., Czech Rep. (2005)

11. J. Horsky, et al., AISTech, Iron\&Steel Techn. Conf. \& exp., Charlotte, USA (2005)

12. M. Raudensky, J. Horsky, Ironm. \& Steelm. 32, 2 (2005)

13. R.A. Richard, R. Harding, Ch. Beckermann, Metall. \& Mater. Transactions, 34B, 297 (2003)

14. J. Stetina, et. al., Proc. of $13^{\text {th }}$ Inter. Heat Trans. Conf., Sydney, Australia (2006) 